BMJ

Open

Gastroenterology

\title{
Infiltrative tumour growth pattern correlates with poor outcome in oesophageal cancer
}

\author{
Maelle Anciaux (D) , ${ }^{1}$ Pieter Demetter (D) , ${ }^{2}$ Roland De Wind (D) , ${ }^{2}$ \\ Maria Gomez Galdon (D) ,2 Sylvie Vande Velde, ${ }^{3,4}$ Gaspard Lens, ${ }^{5}$ \\ Ligia Craciun (D) , ${ }^{2}$ Amélie Deleruelle, ${ }^{1}$ Denis Larsimont (D) , ${ }^{2}$ Tom Lenaerts (D) , 3,4 \\ Francesco Sclafani (D) , ${ }^{1,6}$ Amélie Deleporte (D) , ${ }^{6}$ Vincent Donckier (D) , \\ Alain Hendlisz (D) , ${ }^{6}$ Caroline Vandeputte (D) ${ }^{1}$
}

To cite: Anciaux M, Demetter P, De Wind R, et al. Infiltrative tumour growth pattern correlates with poor outcome in oesophageal cancer. BMJ Open Gastro 2020;7:e000431. doi:10.1136/ bmjgast-2020-000431

$\mathrm{AH}$ and CV contributed equally.

Received 29 April 2020

Revised 12 May 2020

Accepted 22 May 2020

Check for updates

(C) Author(s) (or their employer(s)) 2020. Re-use permitted under CC BY-NC. No commercial re-use. See rights and permissions. Published by BMJ.

${ }^{1}$ Digestive Oncology Laboratory, Institut Jules Bordet, Bruxelles, Belgium

${ }^{2}$ Department of Pathology, Institut Jules Bordet, Bruxelles, Belgium

${ }^{3}$ Machine Learning Group, ULB, Bruxelles, Belgium

${ }^{4}$ Interuniversity Institute of Bioinformatics in Brussels (ULB-VUB), Brussels, Belgium ${ }^{5}$ Computer Science Unit, Haute Ecole Leonard de Vinci Institut Paul Lambin, Bruxelles, Belgium ${ }^{6}$ Gastrointestinal Oncology Unit, Medical Oncology, Institut Jules Bordet, Bruxelles, Belgium ${ }^{7}$ Department of Surgery, Institut Jules Bordet, Bruxelles, Belgium

Correspondence to

Dr Alain Hendlisz;

alain.hendlisz@bordet.be

\section{ABSTRACT}

Objective Oesophageal cancer $(\mathrm{OEC})$ is an aggressive disease with a poor survival rate. Prognostic markers are thus urgently needed. Due to the demonstrated prognostic value of histopathological growth pattern (HGP) in other cancers, we performed a retrospective assessment of HGP in patients suffering from invasive $\mathrm{OEC}$.

Design A first cohort composed of 89 treatment-naïve operated patients with $\mathrm{OEC}$ from The Cancer Genome Atlas (TCGA) public database was constituted, from which H\&E images and RNA-sequencing data were retrieved. Next, a second cohort composed of 99 patients with OEC treated and operated in a Belgian hospital was established. $\mathrm{H} \& \mathrm{E}-$ stained sections and extracted tumorous RNA were obtained from the samples. HGP were assessed on H\&E slides as infiltrative (IGP) or expansive (EGP). TCGA RNAsequencing data were analysed through the gene set enrichment analysis and Cytoscape softwares. Real-time quantitative PCR (qPCR) experiments were performed to assess gene expression in the Belgian cohort.

Results IGP patients displayed a grim prognosis compared with EGP patients, while IGP was found as associated with numerous lymphovascular emboli and perinervous infiltrations. Analyses of the TCGA expression data showed that angiogenesis, epithelial-tomesenchymal transition (EMT) and inflammation were significantly upregulated in IGP compared with EGP samples. qPCR experiments of three genes appearing as highly upregulated in each pathway showed no difference in expression according to the HGP.

Conclusion The current study demonstrates the poor prognostic value carried by IGP in OC and suggests angiogenesis, EMT and inflammation as key carcinogenetic pathways upregulated in this pattern.

\section{INTRODUCTION}

Over the past decades, intensive research has led to the consensus that cancer is a genetic disease, resulting from mutations acquired by the tumour cells. Oncogenes and tumour suppressor genes were designated as driver events in oncogenesis. More recently, tumour-extrinsic factors were demonstrated
Summary box

What is already known about this subject ?

- Histopathological growth pattern (HGP) have been observed in different cancer settings and carry distinct prognosis values.

- In oesophageal cancer (OEC), the scarce literature shows that patients suffering from an expansive growth pattern (EGP) tumour display a better survival than patients displaying an infiltrative growth pattern (IGP) tumour.

- Nevertheless, the biological pathways underlying these distinct morphological profiles are currently unclear.

What are the new findings ?

- Adverse risk factors such as lymphovascular emboli and perinervous infiltrations are correlated with IGP profiles, carrying the poorest prognosis.

- Cancer hallmarks such as angiogenesis, epithelialto-mesenchymal transition and inflammation are enhanced in IGP compared with EGP samples.

How might it impact on clinical practice in the foreseeable future?

These findings underline the need to consider this clinical parameter when composing clinical cohorts.

- As IGP seems to rely more heavily on specific targetable hallmarks, these findings may be of interest in the development of precision medicine in OEC.

as essential in tumourigenesis. These include immune cells and stromal cells or extracellular matrix (ECM) components. Collectively designated under the term of 'tumour microenvironment' (TME) actors, they play a role in several hallmarks of cancer. ${ }^{1}$ Genetic changes, and potentially TME alterations associated with tumour growth and spread, result in observable morphological profiles of the tumour, suggesting that the tumour morphology is a potential surrogate of activated oncogenic processes. $^{2}$ 

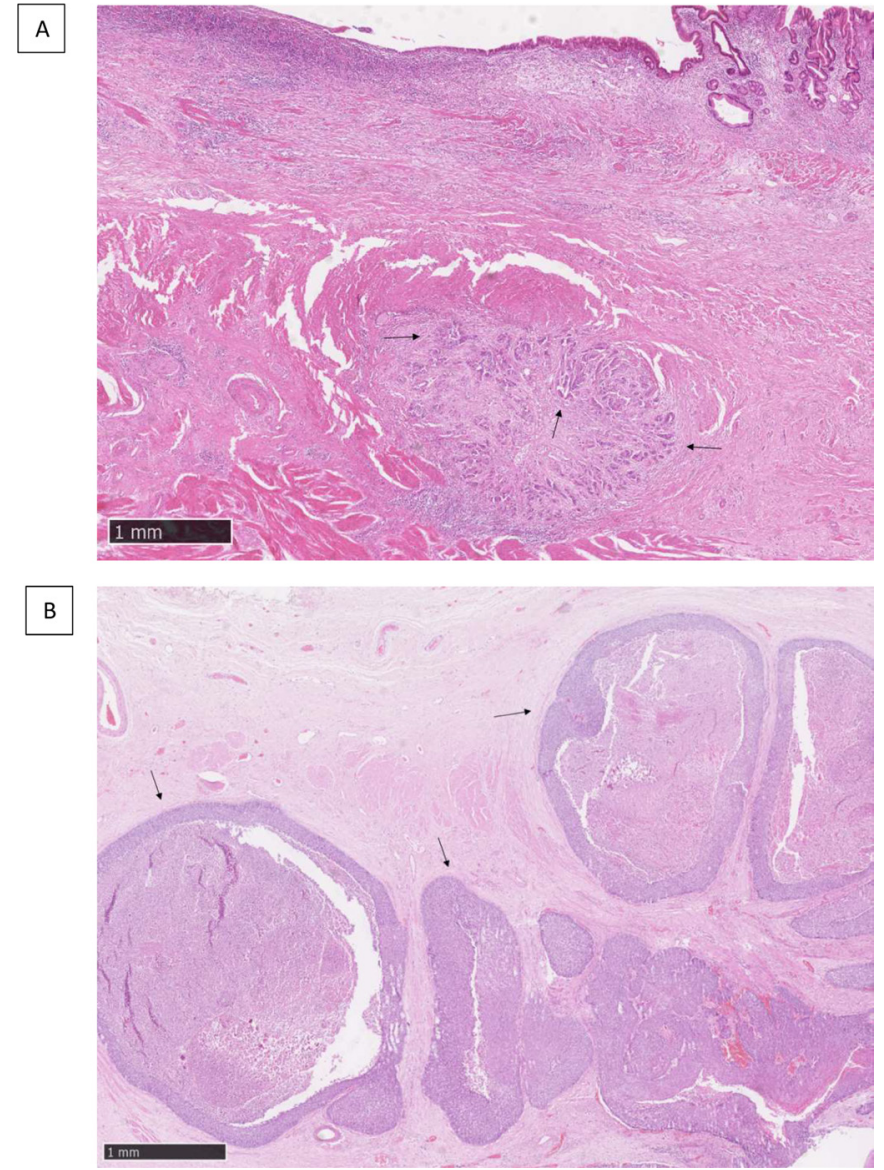

Figure 1 H\&E slide of $(A)$ the infiltrative histopathological growth pattern displaying cords of tumour cells (arrows), (B) the expansive histopathological growth pattern with characteristic sheets of tumour cells (arrows). The scale is depicted in the lower left corner of each image.

The histopathological growth pattern (HGP) describes the interface between the tumour border and the surrounding healthy tissue. It is assessed by light microscopy on H\&E-stained tissue sections, easily performed and readily available. This accessibility has yielded research on HGP and their prognostic impact. Nevertheless, there is no universally applicable pathological classification scheme that would classify any patient with cancer according to the HGP. ${ }^{3}$

HGP have been mostly described in colorectal cancer (CRC) setting. CRC HGP is either infiltrating when the tumour invaded in a diffuse manner with widespread penetration into normal tissue or pushing if well circumscribed. The infiltrating pattern is an independent adverse prognostic factor in $\mathrm{CRC}^{45}$ and is associated with the aggressive mutation $B R A F^{6}$ In contrast, the pushing pattern tumours are at lower risk for metastases and are often correlated to microsatellite instability status. ${ }^{7}$ Thus, HGP assessment is well established in CRC diagnostic pathology for prognosis stratification. ${ }^{8}$

Deeper molecular investigations have been carried in colorectal liver metastases (CRLM), in which three HGP have been established and confirmed in international guidelines ${ }^{910}: 1$ ) the desmoplastic pattern, where the metastasis is separated from the liver parenchyma by a rim of connective tissue; 2) the replacement pattern, where tumour cells infiltrate the liver, disrupting its microscopic architecture and replacing the hepatocytes; 3) the pushing pattern, where liver cells at the tumour-normal parenchyma interface are pushed away and compressed by the tumorous lesion. ${ }^{10} 11$ These HGP display distinct microenvironment features; desmoplastic tumours generate blood vessels in the desmoplastic rim, by angiogenesis. There is often a dense lymphocytic infiltrate at the interface of the desmoplastic and liver tissues, as confirmed by higher levels of inflammatory genes in these tumours. On the opposite, in the replacement pattern, cancer cells form cell plates in continuity with the hepatocytes, enabling them to co-opt the blood vessels at the interface, without using neoangiogenesis. Lymphocytes are not observed within the tumour or in the invasive margins. ${ }^{2}$ A correlation between the metastasis and the primary CRC HGP has been suggested. ${ }^{12}$

The desmoplastic subgroup is associated with a better prognosis as compared with the replacement or pushing subgroups. The lymph node status of the primary tumour, the absence or presence of metastasis within 1 year after resection of the primary CRC and the systemic treatment prior resection differ significantly in the different HGP subgroups. ${ }^{10}$ Indeed, a significant association between neoadjuvant chemotherapy and the presence of desmoplastic HGP in colorectal liver metastases was shown. ${ }^{13}$ Moreover, a post-treatment increased prevalence of the replacement HGP in patients that progressed following treatment with chemotherapy+bevacizumab was observed..$^{14}$

The aggressiveness of oesophageal cancer's (OEC) natural history warrants the evaluation of its malignant potential through the identification of relevant prognostic factors. ${ }^{3}$ In this context, two major HGP have

Table 1 Characteristics of primers according to the manufacturer

\begin{tabular}{lllll}
\hline Company & Assay ID & Targeted gene & Amplicon length (bp) & Assay design \\
\hline ThermoFisher Scientific & Hs00266705_g1 & GAPDH & 74 & Probe spans exons \\
ThermoFisher Scientific & Hs99999906_m1 & PGK1 & 75 & Probe spans exons \\
ThermoFisher Scientific & Hs01552593_m1 & OLR1 & 68 & Probe spans exons \\
ThermoFisher Scientific & Hs01113713_m1 & SFRP4 & 65 & Probe spans exons \\
ThermoFisher Scientific & Hs00171065_m1 & CXCL9 & 60 & Probe spans exons \\
\hline
\end{tabular}


Table 2 TCGA and Belgian cohort patients' clinical characteristics

\begin{tabular}{|c|c|c|}
\hline Parameter & $\begin{array}{l}\text { TCGA cohort, } \\
\mathrm{n}=89\end{array}$ & $\begin{array}{l}\text { Belgian cohort, } \\
\mathrm{n}=99\end{array}$ \\
\hline Sex & N (\%) & N (\%) \\
\hline Female & $12(13.5)$ & $24(24.2)$ \\
\hline Male & $77(86.5)$ & $75(75.8)$ \\
\hline \multirow[t]{2}{*}{ Age } & Median (IQR) & Median (IQR) \\
\hline & $\begin{array}{l}58.8(53.4- \\
67.975)\end{array}$ & $61.4(56.3-69.2)$ \\
\hline Histological type & N (\%) & N (\%) \\
\hline Adenocarcinoma & 35 (39.3) & $61(61.6)$ \\
\hline Squamous cell carcinoma & $54(60.7)$ & $38(38.4)$ \\
\hline Histological grade & N (\%) & $\mathbf{N}(\%)$ \\
\hline Well differentiated & $14(15.7)$ & $19(19.2)$ \\
\hline Moderately differentiated & $36(40.45)$ & $58(58.6)$ \\
\hline Poorly differentiated & $27(30.35)$ & $22(22.2)$ \\
\hline Unknown & $12(13.5)$ & $0(0)$ \\
\hline Location & N (\%) & N (\%) \\
\hline Upper third & $4(4.5)$ & $15(15.15)$ \\
\hline Middle third & $21(23.6)$ & $19(19.2)$ \\
\hline Lower third & $61(68.5)$ & 65 (65.65) \\
\hline Unspecified & $3(3.4)$ & $0(0)$ \\
\hline Tumour depth & $\mathbf{N}(\%)$ & $\mathbf{N}(\%)$ \\
\hline T1 & $15(16.85)$ & $23(23.2)$ \\
\hline T2 & $25(28.1)$ & $19(19.2)$ \\
\hline T3 & $45(50.55)$ & $50(50.5)$ \\
\hline T4 & $4(4.5)$ & $3(3.05)$ \\
\hline Unspecified & $0(0)$ & $4(4.05)$ \\
\hline Lymph node metastasis & N (\%) & $\mathbf{N}(\%)$ \\
\hline No & $36(40.4)$ & $43(43.4)$ \\
\hline N1 & $40(45)$ & $33(33.3)$ \\
\hline N2 & $8(9)$ & $10(10.1)$ \\
\hline N3 & $4(4.5)$ & $6(6.05)$ \\
\hline Unspecified & $1(1.1)$ & $7(7.05)$ \\
\hline Smoker & N (\%) & N (\%) \\
\hline Smoker & $46(51.7)$ & $61(61.6)$ \\
\hline Non-smoker & $26(29.2)$ & $37(37.4)$ \\
\hline Unspecified & $17(19.1)$ & $1(1)$ \\
\hline Drinker & N (\%) & N (\%) \\
\hline Drinker & $39(43.8)$ & $51(51.5)$ \\
\hline Non-drinker & $12(13.5)$ & $46(46.5)$ \\
\hline Unspecified & $38(42.7)$ & $2(2)$ \\
\hline HGP & N (\%) & $\mathbf{N}(\%)$ \\
\hline IGP & $41(46)$ & $59(59.6)$ \\
\hline EGP & $48(54)$ & $40(40.4)$ \\
\hline
\end{tabular}

EGP, expansive growth pattern; HGP, histopathological growth pattern; IGP, infiltrative growth pattern; TCGA, The Cancer Genome Atlas.

been described for OEC by WHO: the expansive growth pattern (EGP) and the infiltrative growth pattern (IGP). Similar to CRC, EGP is characterised by a broad and smooth invasion front with little or no tumour cell dissociation, whereas IGP shows an irregular invasion front and a marked tumour cell dissociation. The degree of desmoplastic or inflammatory stromal reaction is extremely variable. ${ }^{15}$ Nakanishi et al were the first to report the poor survival associated with cancers presenting scattered tumour nests. $^{16}$

Common biological processes, based on the interplay between cancer and the organ microenvironment, may thus be responsible for the HGP in different organs. It is though unclear whether these distinct HGP require different therapeutic strategies. ${ }^{10}$ Furthermore, the lack of common HGP between the different cancers limits the comparison of the HGP impact on outcome, as well as the study of their underlying cell signalling processes. This study aims primarily to assess the prognostic value of HGP in OEC, and secondarily to appraise the underlying biological processes associated with each HGP. These investigations will be performed on treatmentnaïve patients from The Cancer Genome Atlas (TCGA) public database. Finally, a second cohort composed of operated patients with or without neoadjuvant treatment will be explored to detect the previous treatment impact on HGP.

\section{METHODS}

\section{Patient characteristics}

TCGA patients

Clinical data, H\&E slides and RNA-sequencing (RNAseq) data from fresh frozen tumorous samples of patients with OEC were retrieved from the National Cancer Institute's Genomic Data Commons (GDC) portal. ${ }^{17}$ Information concerning sample collection and RNAseq pipeline can be found in the corresponding TCGA publication. ${ }^{18}$

Inclusion criteria for TCGA patients into the present study were the following: availability of H\&E slides and RNAseq data from the tumour surgical specimen, appearance of the tumour border on the H\&E slide and established diagnosis of an invasive OEC.

\section{Belgian patients}

Patients who had undergone surgery for invasive OEC from 2005 to 2017 at Institut Jules Bordet, for whom a formalin-fixed, paraffin-embedded (FFPE) tumorous block was retrievable were included in the second cohort.

Table 3 Belgian patients' distribution regarding HGP and treatments

\begin{tabular}{llll}
\hline HGP & $\begin{array}{l}\text { Surgery } \\
\text { only (\%) }\end{array}$ & $\begin{array}{l}\text { Neoadjuvant } \\
\text { CT (\%) }\end{array}$ & $\begin{array}{l}\text { Neoadjuvant } \\
\text { CRT (\%) }\end{array}$ \\
\hline IGP & $18(18.2)$ & $26(26.3)$ & $15(15.15)$ \\
EGP & $16(16.2)$ & $16(16.15)$ & $8(8)$ \\
\hline
\end{tabular}

CRT, chemoradiotherapy; CT, chemotherapy; EGP, expansive growth pattern; HGP, histopathological growth pattern; IGP, infiltrative growth pattern. 
Table 4 Contingency tables for indicated parameter and HGP, regarding the TCGA cohort

\begin{tabular}{|c|c|c|c|}
\hline \multirow{2}{*}{ Parameter } & & \multicolumn{2}{|l|}{ TCGA } \\
\hline & & IGP (\%) & EGP (\%) \\
\hline \multirow{3}{*}{$\begin{array}{l}\text { Histological } \\
\text { type }\end{array}$} & Adenocarcinoma & 19 (21.3) & $16(18)$ \\
\hline & $\begin{array}{l}\text { Squamous cell } \\
\text { carcinoma }\end{array}$ & $22(24.7)$ & $32(36)$ \\
\hline & $P$ value & 0.3 & \\
\hline \multirow{5}{*}{$\begin{array}{l}\text { Histological } \\
\text { grade }\end{array}$} & Well differentiated & $5(5.6)$ & $9(10.1)$ \\
\hline & $\begin{array}{l}\text { Moderately } \\
\text { differentiated }\end{array}$ & $16(18)$ & $20(22.5)$ \\
\hline & Poorly differentiated & $16(18)$ & $11(12.3)$ \\
\hline & Unknown & $4(4.5)$ & $8(9)$ \\
\hline & $P$ value & 0.1 & \\
\hline \multirow[t]{5}{*}{ T stage } & $\mathrm{T} 1$ & $1(1.1)$ & $9(10.1)$ \\
\hline & $\mathrm{T} 2$ & $10(11.2)$ & $14(15.7)$ \\
\hline & T3 & $22(24.7)$ & $16(18.0)$ \\
\hline & Unknown & $8(9.0)$ & $9(10.1)$ \\
\hline & $P$ value & 0.02 & \\
\hline \multirow[t]{6}{*}{ N stage } & NO & 15 (16.9) & $18(20.2)$ \\
\hline & N1 & $10(11.2)$ & $14(15.7)$ \\
\hline & $\mathrm{N} 2$ & $8(9)$ & $9(10.1)$ \\
\hline & N3 & $7(7.9)$ & $2(2.2)$ \\
\hline & Unknown & $1(1.1)$ & $5(5.6)$ \\
\hline & $P$ value & 0.9 & \\
\hline \multirow[t]{4}{*}{ TP53 status } & Non-mutated & $8(9)$ & $8(9)$ \\
\hline & Mutated & $32(36)$ & $35(39.4)$ \\
\hline & Unknown & $1(1.1)$ & $5(5.6)$ \\
\hline & $P$ value & $>0.99$ & \\
\hline \multirow[t]{4}{*}{ Erbb2 status } & Non-amplified & $37(41.6)$ & $38(42.7)$ \\
\hline & Amplified & $3(3.3)$ & $5(5.6)$ \\
\hline & Unknown & $1(1.1)$ & $5(5.6)$ \\
\hline & $P$ value & 0.7 & \\
\hline \multirow{4}{*}{$\begin{array}{l}\text { CDKN2A } \\
\text { status }\end{array}$} & Epigenetic silencing & $29(32.6)$ & $37(41.6)$ \\
\hline & No silencing & $11(12.4)$ & $6(6.7)$ \\
\hline & Unknown & $5(5.6)$ & $1(1.1)$ \\
\hline & $P$ value & 0.17 & \\
\hline \multirow{5}{*}{$\begin{array}{l}\text { OESCC } \\
\text { subtype }\end{array}$} & C1 & 12 (22.2) & 16 (29.6) \\
\hline & $\mathrm{C} 2$ & 9 (16.7) & $13(24.1)$ \\
\hline & C3 & $0(0)$ & $2(3.7)$ \\
\hline & Unknown & $1(1.1)$ & $1(1.9)$ \\
\hline & P value & 0.7 & \\
\hline
\end{tabular}

All percentages are relative to the entire cohort, except OESCC subtype: relative to OESCC samples only. T stage and N stage concern the PTNM evaluation. Fisher's exact test was performed using the core package of $R$.

EGP, expansive growth pattern; IGP, infiltrative growth pattern; OESCC, oesophageal squamous cell carcinoma; TCGA, The Cancer Genome Atlas.
As oesophageal surgery is uncommon for nontumourous indication, control normal oesophageal tissue were retrieved from proximal margin blocks of patients operated for gastric cancer. A total absence of tumour cells and inflammatory infiltrate was required to consider the tissue as normal tissue.

\section{HGP assessment of both cohorts}

A minimum of $10 \%$ of residual tumorous area over total tissue area was required to representatively assess HGP on the H\&E diagnostic slide. HGP was qualitatively classified by a pathologist experienced in gastrointestinal (GI) oncology (PD) as either EGP if solid sheets of tumour cells present a well-demarcated tumour-stromal interface, or IGP if cords of tumour cells infiltrate the surrounding stroma in a spray-like pattern (figure 1).

\section{Bioinformatical analyses of the TCGA cohort Data retrieval}

RNAseq raw counts data were downloaded from the GDC portal ${ }^{17}$ and normalised into counts per millions. A prefiltering step removed the low counts genes (total counts for all patients below 10 reads) before final normalisation using Deseq2 R package. ${ }^{19}$

\section{Gene set enrichment analysis}

Gene set enrichment analysis (GSEA), developed at the Broad Institute, was then conducted on this set of data. Using hallmarks predefined gene signatures from the Molecular Signatures Database, genes were ranked according to their fold change in IGP versus EGP, and an enrichment score (ES) ranging from -1 to 1 was calculated. Typically, not all members of the gene set will participate in the ES. Hence, a leading-edge subset of genes among the gene set is defined and gathers the genes contributing the most to the $\mathrm{ES}{ }^{20}$

\section{Cytoscape}

The differentially expressed genes found with the Deseq 2 $\mathrm{R}$ package were also used to perform analyses using the Cytoscape software. This open source software is intended for molecular interaction network and biological pathways visualisation from gene expression profiles. ${ }^{21}$ The gene sets from the Reactome pathways database were explored with this tool. ${ }^{22}$

\section{Estimating the Proportion of Immune and Cancer cells}

The tool Estimating the Proportion of Immune and Cancer cells (EPIC), developed by Gfeller lab at the University of Lausanne ${ }^{23}$ was also run on this dataset with the EPIC R package. To this aim, raw counts were normalised into transcripts per million.

\section{Gene expression experiments in the Belgian cohort} Tumour macrodissection

Tumour cells on diagnostic H\&E slides were marked by experienced GI pathologists (PD and MGG). Manual macrodissection of marked regions was performed to increase the tumorous content of the sample. A standard 

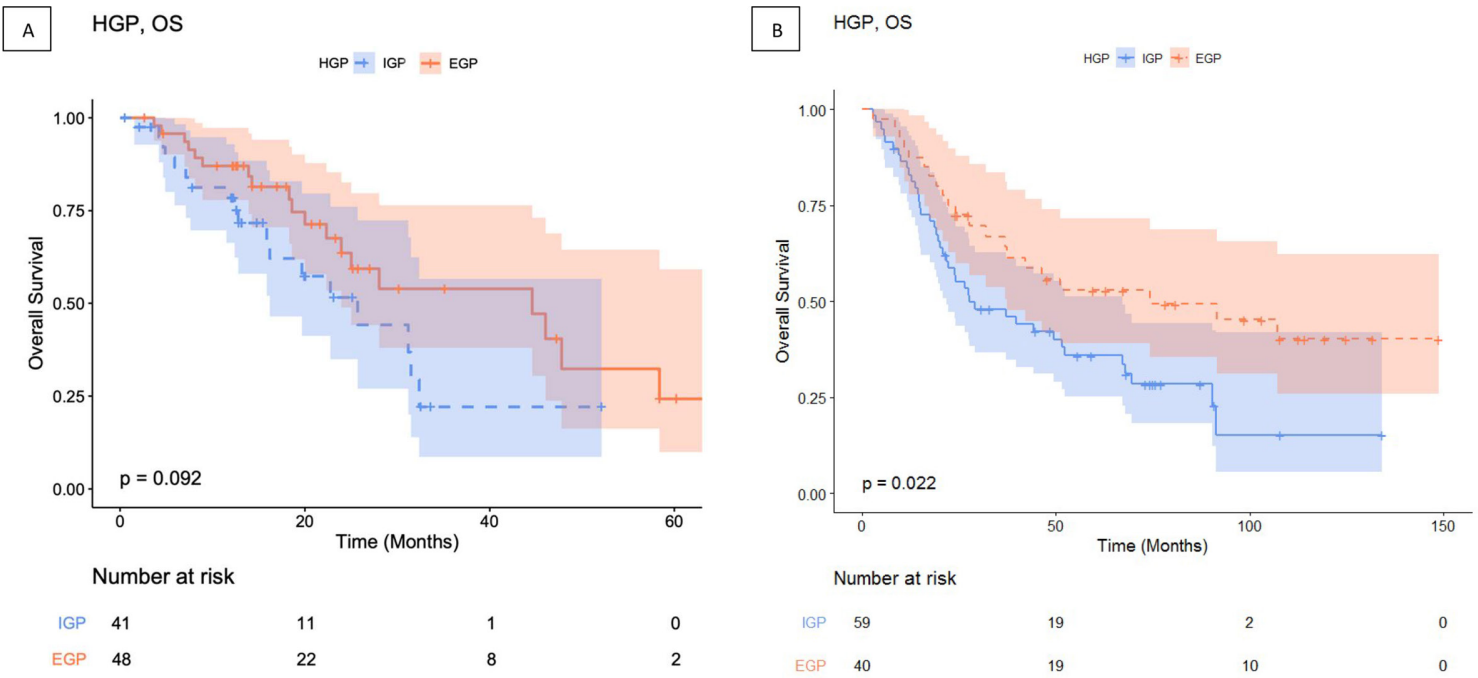

Figure 2 Kaplan-Meier overall survival (OS) of (A) the 89 patients with oesophageal cancer (OEC) of the The Cancer Genome Atlas (TCGA) cohort for infiltrative growth pattern (IGP) and expansive growth pattern (EGP), (B) the 99 patients with OEC of the Belgian cohort for IGP and EGP. EGP is an indicator of better survival. Forest plot figure was drawn using the survminer $\mathrm{R}$ package.

of eight sections of $5 \mu \mathrm{m}$ were obtained using a microtome. This number could be adapted according to the size of the delineated tumour area. Two sections were also obtained for further immunohistochemistry (IHC) experiments.

Finally, an additional $\mathrm{H} \& \mathrm{E}$ staining was performed after cutting the sections intended for extraction and IHC, to ensure that the required minimum of $10 \%$ of residual tumorous area was respected.

\section{IHC experiments}

Mounted slides were dried overnight in a $37^{\circ} \mathrm{C}$ incubator and stained within 24 hours after cutting. Dual IHC for CD3/CD20 and CD4/CD8 were performed following Buisseret et al protocol. ${ }^{24}$ IHC were scored by a pathologist experienced in assessment of inflammatory infiltrates (RDW) for percentage of tumorous surface occupation, either in the intratumoural compartment or in the migration front. On control samples, IHC were scored on the total surface of the tissue. Absence or presence of tertiary lymphoid structures (TLS) was assessed on CD3/CD20 slides. Presence of plasmocytes in the tumorous area was categorised from absence to strong presence following four categories.

\section{DNA and RNA extraction}

Simultaneous DNA and RNA extraction from FFPE samples was performed within 24 hours of cutting using the Allprep DNA/RNA FFPE kit (Qiagen, Hilden, Germany) and following the manufacturer's instructions.

The RNA amount was quantified using a Qubit 3.0 fluorometer (Invitrogen, Life Technologies, USA) and the Qubit dsRNA BR assay kit (Invitrogen, Life Technologies).

RNA samples quality was assessed by BioAnalyzer experiments following the manufacturer's instructions (DNA High Sensitivity Bioanalyzer (Agilent, USA)).
Quantitative PCR experiments

Retrotranscription of RNA into complementary DNA (cDNA), preamplification of targeted genes and real-time quantitative PCR (qPCR) experiments were performed following the method described by Gu-Trantien et al. ${ }^{25}$ An amount corresponding to $20 \mathrm{ng}$ of initial RNA was added per qPCR well and the following programme was run on the Applied Biosystems QuantStudio 3 Real-Time PCR System: $50^{\circ} \mathrm{C}$ for $2 \mathrm{~min}, 95^{\circ} \mathrm{C}$ for $10 \mathrm{~min}$, then 40 cycles at $95^{\circ} \mathrm{C}$ for $15 \mathrm{~s}$ and $60^{\circ} \mathrm{C}$ for $1 \mathrm{~min}$. Samples were run in duplicates. Primers used for preamplification and qPCR experiments are detailed in table 1. Genomic DNA was used to confirm the specificity of primers binding to cDNA.

Material obtained from tonsil samples was used as exogenous positive control for CXCL9. A no template control (NTC) was also replicated for each mix on each plate.

We considered the first three GSEA hallmarks statistically enriched in IGP compared with EGP to choose one gene per hallmark to investigate in qPCR experiments. In these hallmarks' gene sets, the genes of interest were chosen on the following Deseq 2 criteria: $\log 2$ FoldChange $(\log 2 \mathrm{FC})$ of at least 1 and an adjusted $\mathrm{p}$ value $<0.05$. Moreover, an association between the gene of interest and the biological signature investigated had to be established in the literature.

For each gene, the mean cycle threshold (CT) of samples' duplicates was calculated. Then, the median of these CT was set as threshold for high and low expression in survival curves. CT values above 32 cycles were considered as probable background noise and not included in the analysis.

\section{Statistical analyses}

The primary objective of the study was to assess the association between HGP and overall survival (OS). For the 
Table 5 Contingency tables for indicated parameter and HGP regarding the Belgian cohort

\begin{tabular}{|c|c|c|c|}
\hline \multirow{2}{*}{ Parameter } & & \multicolumn{2}{|c|}{ Belgian cohort } \\
\hline & & IGP (\%) & EGP (\%) \\
\hline \multirow[t]{3}{*}{ Histological type } & Adenocarcinoma & $40(40.4)$ & $21(21.2)$ \\
\hline & $\begin{array}{l}\text { Squamous cell } \\
\text { carcinoma }\end{array}$ & $19(19.2)$ & 19 (19.2) \\
\hline & $P$ value & 0.14 & \\
\hline \multirow[t]{4}{*}{ Histological grade } & Well differentiated & $12(12.1)$ & $7(7.1)$ \\
\hline & $\begin{array}{l}\text { Moderately } \\
\text { differentiated }\end{array}$ & $32(32.3)$ & $26(26.3)$ \\
\hline & $\begin{array}{l}\text { Poorly } \\
\text { differentiated }\end{array}$ & $15(15.1)$ & $7(7.1)$ \\
\hline & $P$ value & 0.5 & \\
\hline \multirow[t]{6}{*}{ T stage } & $\mathrm{T} 1$ & $9(9.1)$ & $7(7.1)$ \\
\hline & T2 & $13(13.1)$ & $6(6.1)$ \\
\hline & T3 & 32 (32.3) & $21(21.2)$ \\
\hline & $\mathrm{T} 4$ & $2(2.0)$ & $2(2.0)$ \\
\hline & Unknown & $3(3.0)$ & $4(4.0)$ \\
\hline & $P$ value & 0.8 & \\
\hline \multirow[t]{6}{*}{$\mathrm{N}$ stage } & NO & $17(17.2)$ & 19 (19.2) \\
\hline & N1 & $32(32.3)$ & $11(11.1)$ \\
\hline & N2 & $2(2.0)$ & $1(1.0)$ \\
\hline & N3 & $1(1.0)$ & $0(0.0)$ \\
\hline & Unknown & $7(7.1)$ & $9(9.1)$ \\
\hline & $P$ value & 0.04 & \\
\hline \multirow[t]{4}{*}{ Treatment } & Surgery only & $18(18.2)$ & $16(16.2)$ \\
\hline & CT & $26(26.3)$ & $16(16.2)$ \\
\hline & CRT & $15(15.1)$ & $8(8)$ \\
\hline & $P$ value & 0.6 & \\
\hline \multirow{4}{*}{$\begin{array}{l}\text { Lymphovascular } \\
\text { embolus }\end{array}$} & Presence & $25(25.2)$ & $2(2)$ \\
\hline & Absence & $21(21.2)$ & $16(16.2)$ \\
\hline & Unknown & $13(13.1)$ & $22(22.2)$ \\
\hline & $P$ value & 0.002 & \\
\hline \multirow{4}{*}{$\begin{array}{l}\text { Perinervous } \\
\text { infiltration }\end{array}$} & Presence & $24(24.2)$ & $2(2)$ \\
\hline & Absence & $20(20.2)$ & $14(14.2)$ \\
\hline & Unknown & $15(15.1)$ & $24(24.2)$ \\
\hline & $P$ value & 0.004 & \\
\hline
\end{tabular}

T stage and $\mathrm{N}$ stage concern the cTNM evaluation. Fisher's exact test was performed using the core package of $R$. CRT, chemoradiotherapy; CT, chemotherapy; EGP, expansive growth pattern; IGP, infiltrative growth pattern; OESCC, oesophageal squamous cell carcinoma.

univariate analysis, Kaplan-Meier curves were used to compare OS of patients according to their HGP group. Hazard Ratio (HR) and 95\% Confidence Interval (CI) were calculated using Cox proportional hazards model and logrank tests were used to compare survival curves. Fisher's exact test was used to assess the relationship between HGP and clinical parameters in contingency tables. Results were considered statistically significant at the bilateral $\mathrm{p}<0.05$.

The second aim of the study was to assess the association between HGP and differential activation of several biological pathways. As database of multiple gene sets were run on the data, GSEA results were assessed using an adjusted $p$ value, the false discovery rate (FDR), to account for multiple hypothesis testing. ${ }^{20}$ Results with an FDR value $\leq 0.1$ were considered statistically significant. Similarly, the Cytoscape gene sets displaying an FDR value $\leq 0.1$ were considered statistically significant.

In IHC experiments, Mann-Whitney U tests were used to compare the distribution of CD3-CD20-CD4-CD8 regarding HGP, or regarding HGP and preoperative treatments. Fisher's exact test was used to compare the distribution of HGP groups with the four categories of plasmocytes presence and to assess HGP regarding the absence or presence of TLS.

In qPCR experiments, Mann-Whitney $\mathrm{U}$ tests were used to compare the distribution of the HGP groups for each gene expression. Similarly, differences in EPIC immune profiles were assessed using Mann-Whitney $\mathrm{U}$ test.

R V.3.5.1 and GraphPad Prism V.7 were used for statistical analyses.

\section{RESULTS}

\section{Patients' characteristics}

The TCGA cohort and the Belgian cohort, respectively, included 89 and 99 patients with OEC. Their characteristics are described in table 2. The distribution of the Belgian cohort regarding HGP and preoperative treatments is shown in table 3. Fifteen normal control samples were obtained from archived tissues.

\section{Survival and contingency analyses \\ TCGA patients}

IGP is seemingly associated with a poorer outcome compared with EGP. In the TCGA cohort, median OS is respectively 25.7 months (16.2-Not Available (NA)) and 44.6 months (23.9-NA) for IGP and EGP (HR 1.7 (95\% CI 0.87 to 3.35$), \mathrm{p}=0.092$ ).

Contingency tables (table 4) for this cohort show no association between HGP and histological type or grade, N stage, TP53 mutation status, Erbb2 amplification status, CDKN2A silencing status or oesophageal squamous cell carcinoma (OESCC) subtype as established by the TCGA, while higher $\mathrm{T}$ stage samples displayed more often the IGP.

\section{Belgian patients}

In the Belgian cohort, median OS is respectively 27.7 months (21.6-67.3) and 74.3 months (37.4-NA) for IGP and EGP (HR 1.9 (95\% CI 1.1 to 3.2), p=0.022) (figure 2).

In the Belgian cohort (table 5), we found a significantly higher proportion of tumours presenting higher $\mathrm{N}$ stage, lymphovascular emboli or perinervous infiltrations in the IGP group. No association between HGP and previous treatment was found. 

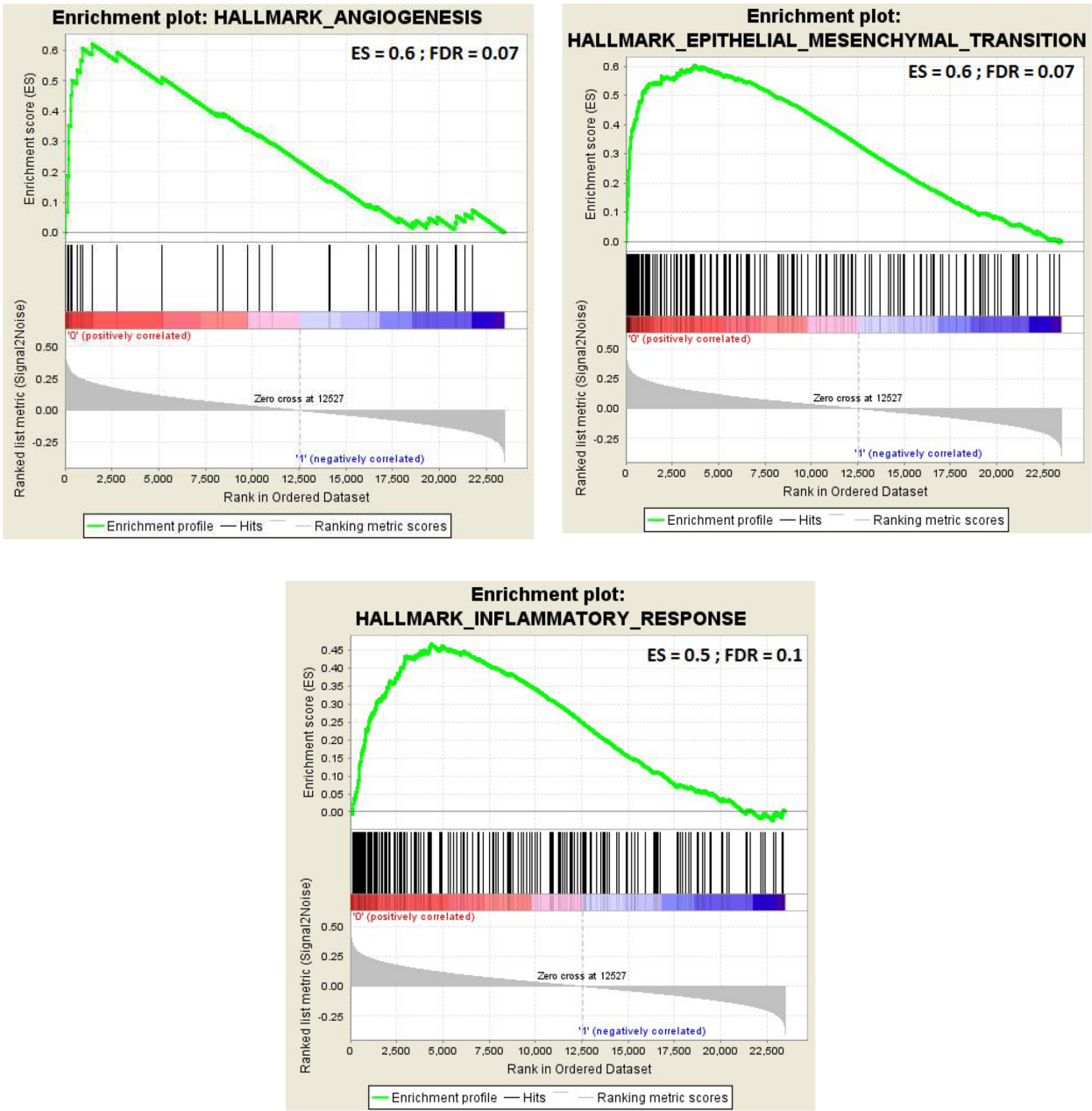

Figure 3 Gene set enrichment analysis plots for infiltrative growth pattern (IGP) compared with expansive growth pattern (EGP) regarding (A) angiogenesis predefined gene set, (B) epithelial-to-mesenchymal transition (EMT) predefined gene set, (C) inflammatory response predefined gene set.

Differential gene expression results

TCGA patients

Gene set enrichment analysis

GSEA investigations were performed to measure the expression of predefined gene sets related to specific biological processes in IGP compared with EGP. Three GSEA gene sets were found with an FDR $\leq 0.1$ (figure 3): angiogenesis, epithelial-to-mesenchymal transition

Table 6 Leading edge subset of GSEA angiogenesis, EMT and inflammatory response gene sets

\begin{tabular}{ll}
\hline Gene set & Leading edge subset \\
\hline Angiogenesis & NRP1, COL3A1, POSTN, TIMP1, FSTL1, VCAN, COL5A2, OLR1, S100A4, LUM, LPL, SPP1, KCNJ8 \\
EMT & PDGFRB, BGN, LOXL1, SFRP4, ECM2, GREM1, FBLN5, NTM, MMP2, FBN1, COL6A3, SGCD, FAP, \\
& DAB2, THY1, MXRA5, DCN, COL3A1, POSTN, SPARC, CTHRC1, COL6A2, TIMP1, PMP22, FSTL1, \\
& ABI3BP, VCAN, LAMA2, TIMP3, FBLN2, COL1A2, PRRX1, THBS2, COL1A1, PCOLCE, COL5A2, TPM1, \\
& NNMT, NID2, CDH11, MMP14, IL6, MGP, THBS1, LRRC15, LUM, VIM, ACTA2, TPM2, CALD1, CXCL12, \\
& MFAP5, ELN, TAGLN, FERMT2, SPP1, HTRA1, GADD45B, COL11A1, GAS1, ADAM12, SPOCK1, SLIT2, \\
& ITGA5, TGM2, COL5A1, MYL9, ITGB1, COL12A1, INHBA, CAP2, GEM, TGFBR3, VCAM1, FGF2, PMEPA1, \\
& FZD8, FN1, ITGAV, EMP3, COL5A3, WIPF1, COL16A1, SLIT3, CALU, EFEMP2, CDH6, GLIPR1, FUCA1, \\
Inflammatory & PLAUR, FLNA, MYLK, SGCB \\
response & MSR1, PTGIR, TIMP1, IL1R1, TNFAIP6, RGS1, C5AR1, GPR132, NMUR1, STAB1, MMP14, IL6, CCL5, \\
& P2R×7, LCP2, SLAMF1, PTGER4, IL15RA, C3AR1, LCK, FPR1, CMKLR1, IL10RA, GPR183, ABCA1, \\
& IL2RB, P2R×4, CYBB, RGS16, CXCL9, CXCR6, ICAM1, ITGA5, CD48, IL10, TNFRSF9, INHBA, IL18RAP, \\
& TNFRSF1B, PIK3R5, CSF3R, OSM, NDP, APLNR, SCARF1, LTA, SLC11A2, NLRP3, GABBR1, AXL, \\
& CCL22, CALCRL, VIP, AQP9, EMP3, SGMS2, CCR7, KCNA3, CSF1, PTPRE, PLAUR, SPHK1, ACVR1B, \\
& KLF6, SELL, EBI3, PDE4B, ITGB3, CD55, CLEC5A, BEST1, IRF1
\end{tabular}




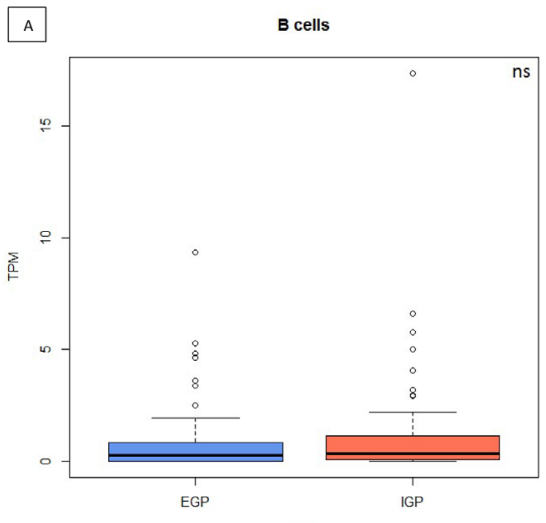

HGP

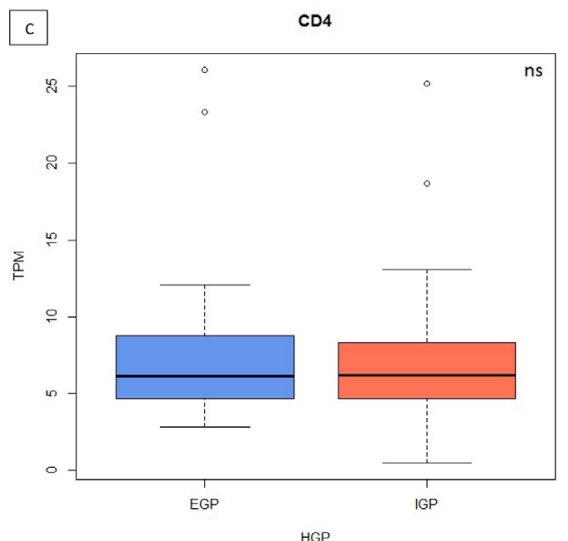

HGP

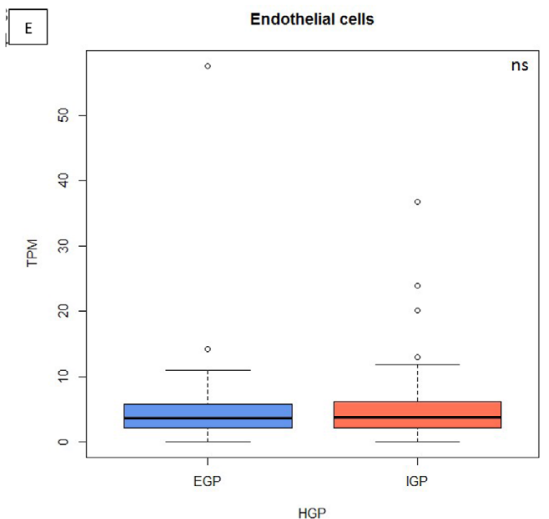

G

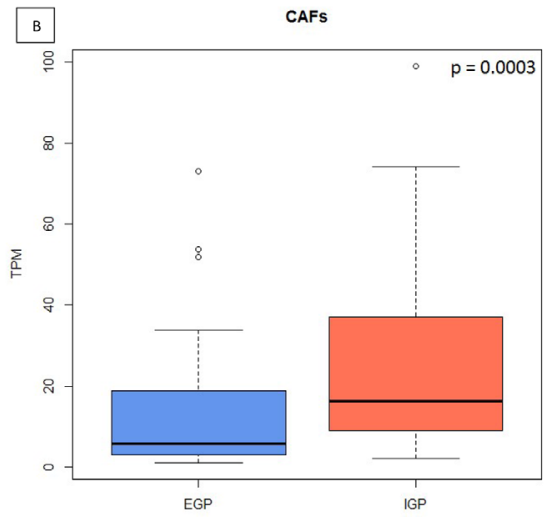

HGP

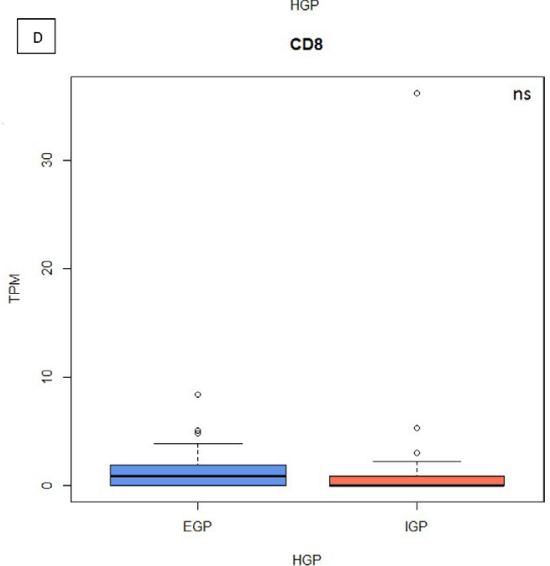

HGP

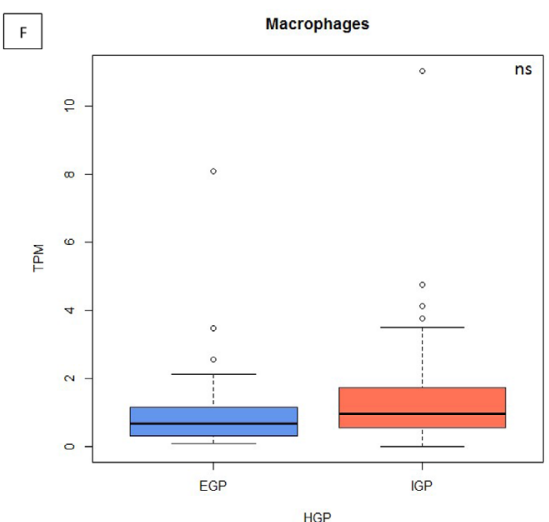

NK

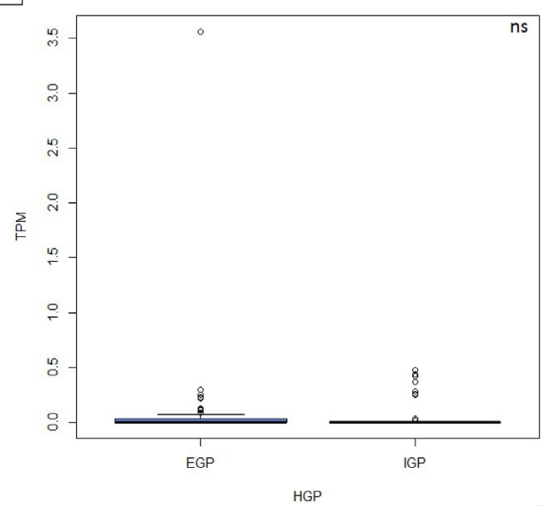

Figure 4 Estimating the Proportion of Immune and Cancer cells (EPIC) box plots of infiltrative growth pattern (IGP) vs expansive growth pattern (EGP) for (A) B cell-related transcripts, (B) cancer-associated fibroblasts (CAFs)-related transcripts, (C) CD4 T cells-related transcripts, (D) CD8 T cells-related transcripts, (E) endothelial cells-related transcripts, (F) macrophagesrelated transcripts, $(\mathrm{G})$ natural killer (NK) cells-related transcripts. ns, not significant. 

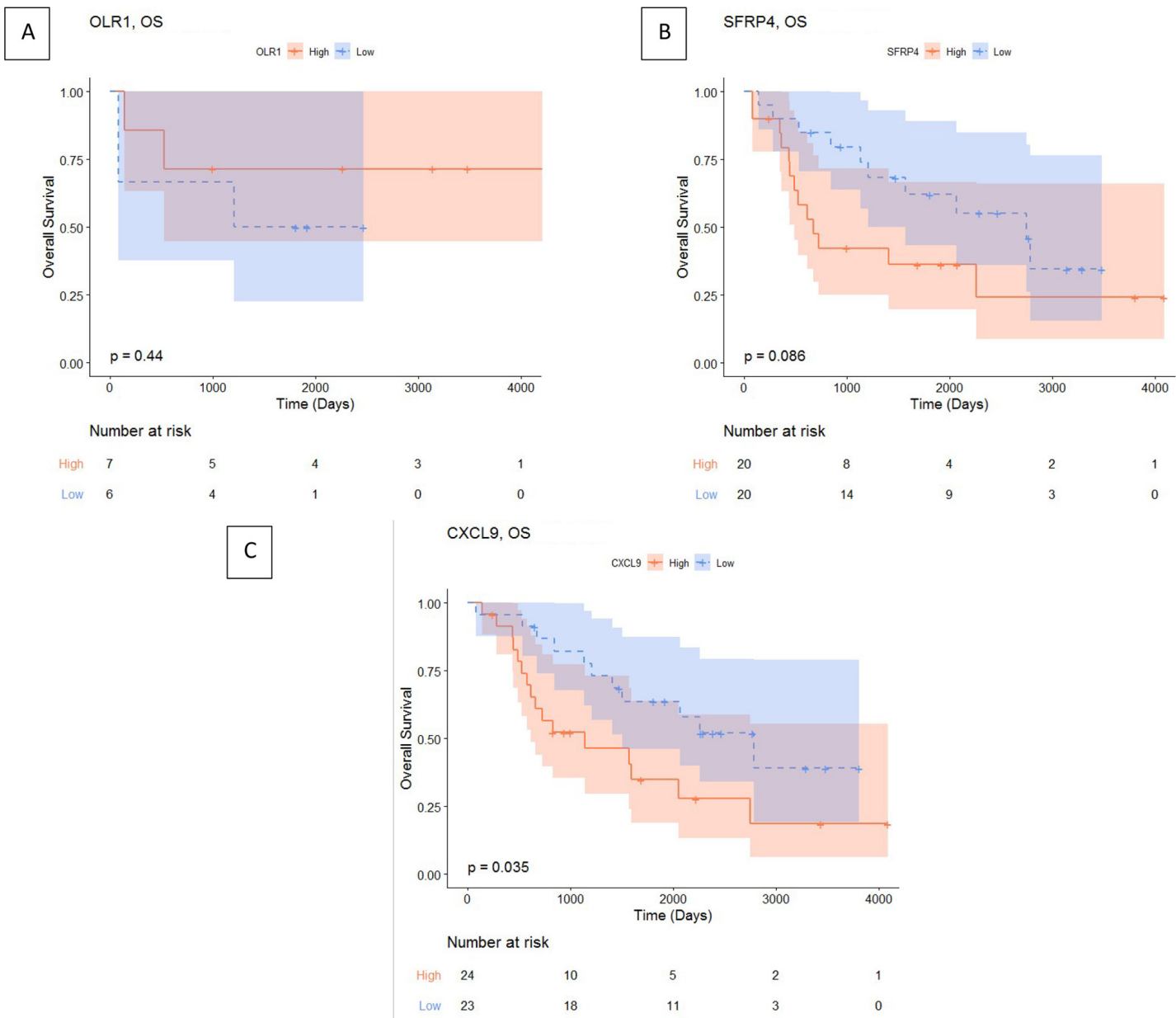

Figure 5 Kaplan-Meier overall survival (OS) of (A) OLR1 expression, (B) SFRP4 expression, (C) CXCL9 expression in the Belgian cohort, using median expression threshold for high and low groups. Figure was drawn using the survminer $\mathrm{R}$ package.

(EMT) and inflammatory response. When comparing infiltrative samples only (oesophageal adenocarcinoma (OEAC) vs OESCG) or expansive samples only (OEAC vs OESCC), no significant enrichment of one of these gene sets was found in one histology relatively to the other $(\mathrm{FDR}>0.3)$.

Among the leading-edge subsets (table 6), OLR1 $(\log 2 \mathrm{FC}=1.3$, adjusted $\mathrm{p}=0.01)$, SFRP4 $(\log 2 \mathrm{FC}=1.8$, adjusted $\mathrm{p}=0.01)$ and CXCL9 $(\log 2 \mathrm{FC}=1.45$, adjusted $\mathrm{p}=0.035$ ) showed respectively established association in the literature with angiogenesis, ${ }^{2627} \mathrm{EMT}^{28} 29$ and inflammation $^{30}{ }^{31}$ and were hence further investigated in qPCR experiments in the Belgian cohort.

\section{Cytoscape}

Using the Reactome pathways database, ECM organisation $\left(\mathrm{FDR}=3.2 \times 10^{-8}\right)$, degradation of the ECM $\left(\mathrm{FDR}=2.9 \times 10^{-4}\right)$, collagen degradation $(\mathrm{FDR}=0.004)$, activation of matrix metalloproteinases $(\mathrm{FDR}=0.01)$, innate immune system $(\mathrm{FDR}=0.02)$ and activation of C3 and C5 (FDR=0.037) were significantly upregulated in IGP versus EGP and concordant with the GSEA findings.

\section{Estimating the Proportion of Immune and Cancer cells}

EPIC analyses did not show any difference for B cells, CD8 cells, CD4 cells, natural killer (NK) cells, endothelial cells and macrophages between IGP and EGP in the TCGA cohort. Cancer-associated fibroblasts (CAFs) were more numerous in IGP than EGP (median IGP vs median EGP: 16.4 vs 5.35, $\mathrm{p}=0.0003$ ) (figure 4).

\section{Belgian patients}

Quantitative PCR

Of the 99 patients included in the Belgian cohort, many RNA samples did not show detectable signal in qPCR (>32 CT), leading to subsequent smaller analysable cohorts (13 patients for OLR1, 40 patients for SFRP4 and 45 patients for $C X C L 9$ ). To investigate a potential RNA quality issue, we tested the samples for two constitutive, supposedly highly expressed genes ${ }^{32}$ : GAPDH and PGK1. These samples also gave poor signal for these two genes.

We performed BioAnalyzer experiments on a subset of 35 samples of the cohort and obtain a median quality, expressed as Distribution Value 200 (DV200) of $12 \%$.

No difference in expression of OLR1 $(\mathrm{p}=0.19)$, SFRP4 $(\mathrm{p}=0.77)$ or $C X C L 9(\mathrm{p}=0.14)$ was found between IGP and EGP. 

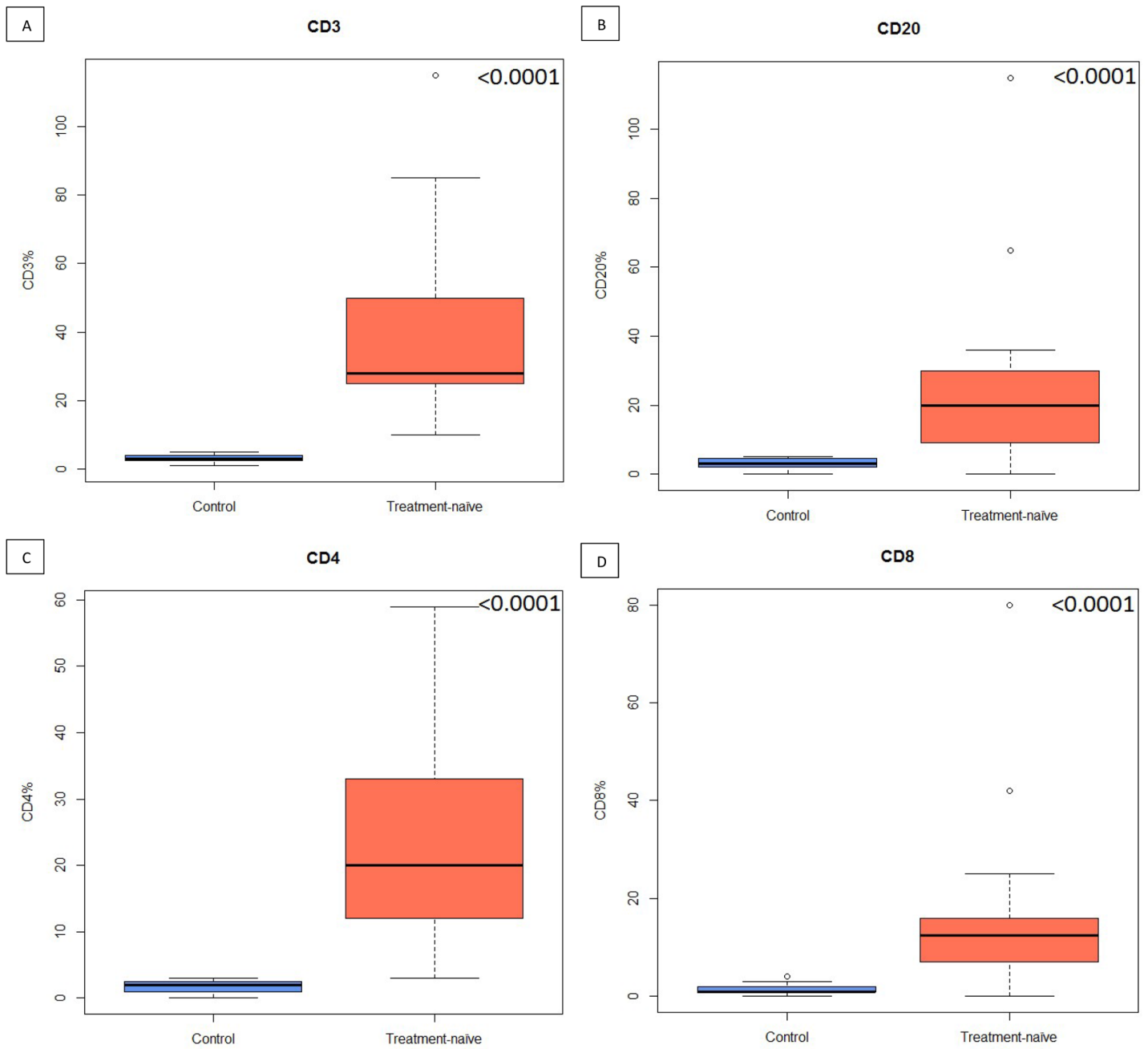

Figure 6 Box plots of control healthy oesophageal cancer (OEC) tissue vs treatment-naïve OEC tumours for: (A) CD3 cells, (B) CD20 cells, (C) CD4 cells and (D) CD8 cells.

The Kaplan-Meier survival curve of CXCL9 showed an improved OS for patients with low expression (HR 0.45 (95\% CI 0.21 to 0.98$)$; $\mathrm{p}=0.035)$. Patients with low expression of SFRP4 seem to display improved survival SFRP4 (HR 0.50 (95\% CI 0.22 to 1.15 ); $\mathrm{p}=0.086$ ). No difference in survival was observed in the smaller groups of patients analysed for OLR1 (HR 0.50 (95\% CI 0.085 to 2.9); $\mathrm{p}=0.44$ ) (figure 5).

\section{IHC}

Although IHC for CD3/CD20 and CD4/CD8 showed that treatment-naïve tumours are significantly more infiltrated in CD3, CD20, CD4 and CD8 than control tissue (figure 6), the stainings did not show any significant difference in immune cells proportions (figure 7), TLS count or plasmocytes frequency between IGP and EGP in the Belgian cohort (table 7). The analysis of immune cells proportions depending on HGP and preoperative treatment showed no association except for a significant decreased infiltration of CD20 in the migration front of IGP samples compared with EGP tumours $(\mathrm{p}=0.04)$.

\section{DISCUSSION}

OEC tumours are aggressive cancers that remain difficult to cure despite novel neoadjuvant approaches that have become progressively standard of care. ${ }^{33}$ This prompts the need for new biomarkers giving insights into tumour's behaviour and food for thoughts about disease management improvements. Overall, our results are concordant with the current literature regarding HGP in OEC and confirm the poor prognostic value of the infiltrative pattern. ${ }^{1634}$

This trend was observed in both cohorts, although with a non-significant trend in the TCGA patients. IGP is also associated with higher $\mathrm{N}$ and $\mathrm{T}$ stage, lymphovascular emboli and perinervous infiltrations, both processes contributing to tumour spread, although results were dissimilar between both cohorts. We found no association between HGP and other clinical parameters such as histological type and grade. Similarly, there was no difference between HGP in any of the tumour genetic alterations investigated, in contrast to CRC. ${ }^{34}$ Nevertheless, only three of the most common mutations found in OEC were tested; it is therefore possible that other 
A

CD3

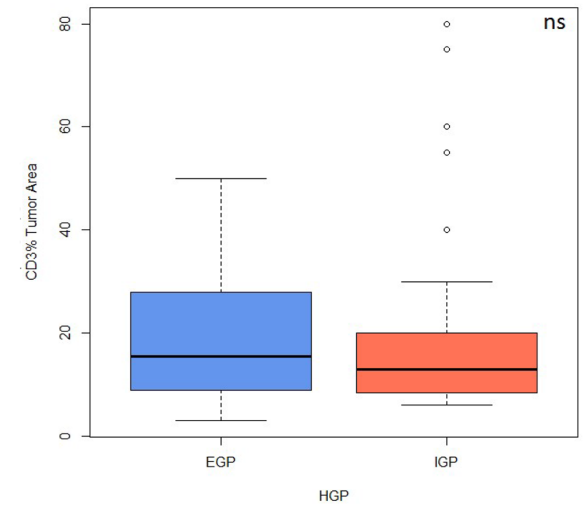

C

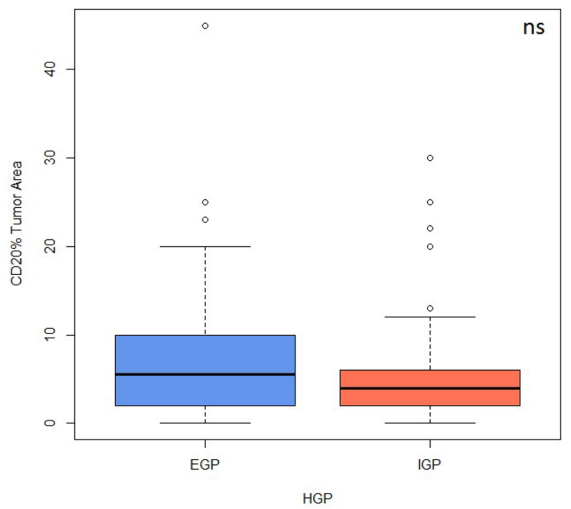

E

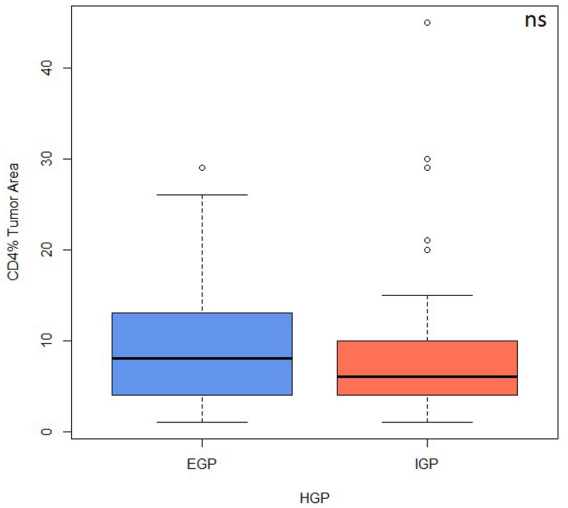

G

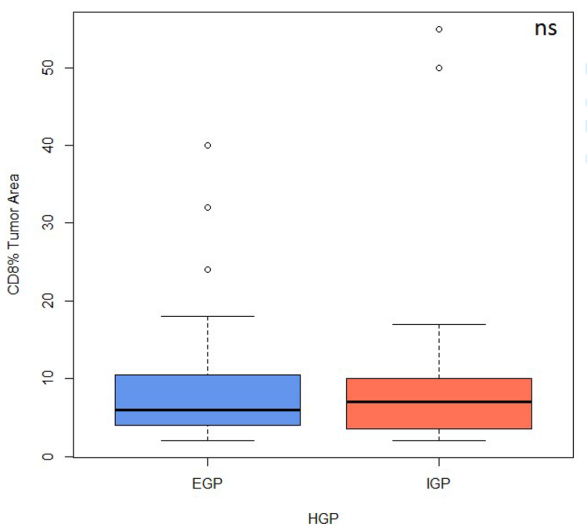

B

CD3

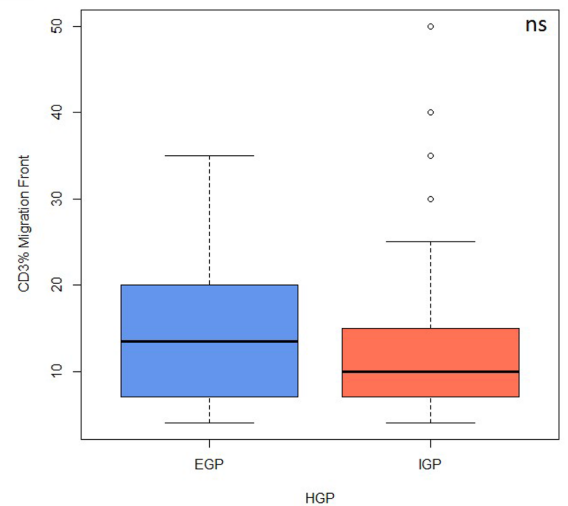

$\mathrm{CD} 20$

D

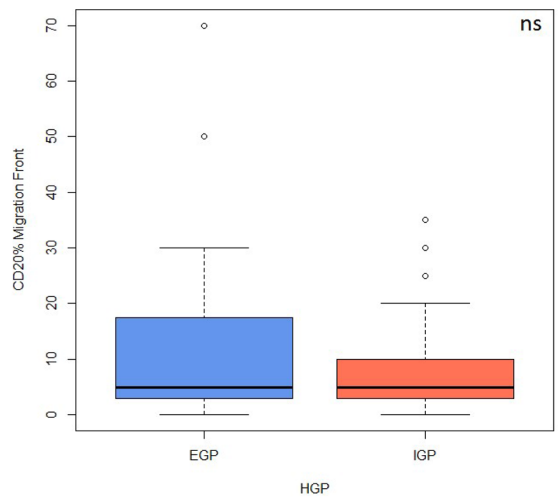

$\operatorname{CD} 4$

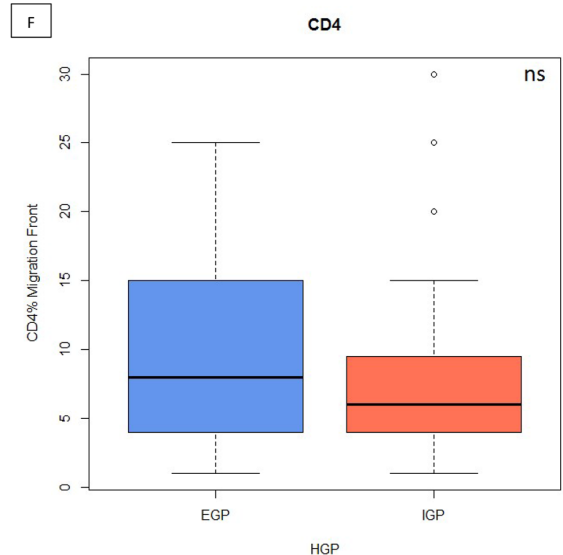

CD8

$\mathrm{H}$

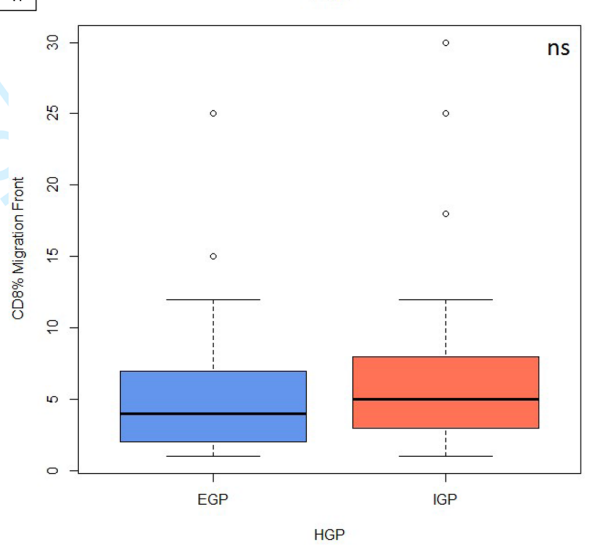

Figure 7 Box plots of infiltrative growth pattern (IGP) vs expansive growth pattern (EGP) in tumourous area (left) or in the migration front (right) for: (A and B) CD3 cells, (C and D) CD20 cells, (E and F) CD4 cells, (G and H) CD8 cells. HGP, histopathological growth pattern; ns, not significant. 
Table 7 Contingency tables for indicated parameter and HGP in the Belgian cohort

\begin{tabular}{lcc}
\hline Parameter & IGP & EGP \\
\hline Plasmatocytes & N (\%) & N (\%) \\
0 & $28(28.3)$ & $9(9.1)$ \\
+ & $9(9.1)$ & $10(10.1)$ \\
++ & $17(17.2)$ & $14(14.1)$ \\
+++ & $5(5)$ & $7(7.1)$ \\
P value & 0.07 & \\
TLS & $\mathbf{N}(\%)$ & $\mathbf{N}(\%)$ \\
Absence & $21(21.2)$ & $16(16.2)$ \\
Presence & $38(38.4)$ & $24(24.2)$ \\
P value & 0.68 & \\
\hline
\end{tabular}

Fisher's exact test was performed using the core package of R. EGP, expansive growth pattern; HGP, histopathological growth pattern; IGP, infiltrative growth pattern; TLS, tertiary lymphoid structure.

less frequent mutations show an association with HGP. Indeed, molecular profiling in lung cancer defined distinct growth pattern-specific gene signatures, not necessarily matching with molecular subtypes established on transcriptional or genomic profiles. ${ }^{35}$

The GSEA investigation conducted in the TCGA cohort identified several signalling networks driving progression that are upregulated in IGP tumours suggesting that angiogenesis, EMT and inflammation may be enhanced in IGP compared with EGP. Such pathways were also found as differentially expressed in HGP in other cancer types such as CRLM and glioblastoma and were associated with distinct prognoses. As described in the literature, ${ }^{18}$ many common pathways are somatically altered in OEAC and OESCC, although the specific genes affected are dissimilar, probably reflecting distinct pathophysiology. The GSEA analyses comparing the same HGP according to distinct histology did not show differences in angiogenesis, EMT and inflammatory response. However, these analyses were performed on groups composed of a low number of patients. Taking into account the current literature and the absence of association between HGP and histology in this study, we suggest that HGP does not rely on the biological pathways differentiating OESCC and OEAC.

Concordantly with EMT, ${ }^{36}$ CAFs were significantly more numerous in IGP than EGP, which is also in concordance with the work of Nakanishi et al, who showed that the pattern with the deepest infiltration tends to display a fibroblastic stroma. ${ }^{16}$ Considering the leadingedge subset associated with the inflammation response, the innate immune system seems particularly active in IGP. Genes participating in macrophage physiological processes (MSR1, $P 2 R \times 7, C S F 1$ ), in granulocyte lineage functions (CSF3R, inflammasome activator NLRP3), in myeloid lineage functions (CCL22, CLEC5A), in NK cells activation (LCP2), in neutrophile recruitment
(NOX2) and complement receptor (C5AR1, C3AR1) or genes regulating the complement system (CD55) were all central components of the inflammatory responseenriched signal found in IGP versus EGP. Similarly, the Cytoscape software pointed the innate immune system and the activation of $\mathrm{C} 3$ and $\mathrm{C} 5$ complement factors as gene sets significantly upregulated in IGP, suggesting a critical role of the innate immune response over the adaptative immune response. Concordantly with these results, the EPIC analysis on the TCGA cohort and the IHC performed in the Belgian cohort did not show any differential proportion in CD8, CD4 and CD20 cells. However, the EPIC analysis did not point to differences in macrophage and NK cells proportions either. Nevertheless, as IGP remains significantly more inflamed in the TCGA analyses, this lead warrants further investigation. Moreover, CRLM desmoplastic patterns correlate with high levels of peritumoural CD4+, CD45RO+ and CD8+ cells and present a distinct cytokinic profile. ${ }^{237}$

In the leading-edge subset generated by the GSEA investigations, OLR1, SFRP4 and CXCL9 genes were shown as significantly highly expressed in IGP compared with EGP. Upregulated by reactive oxygen species and tumour necrosis factor- $\alpha$, OLR1 may activate $\mathrm{NF}-\mathrm{\kappa B}$ signalling and lead to upregulation of proangiogenic markers. In CRC, high expression of OLR1 has also been associated with immunosuppressive TME and worse prognosis, ${ }^{38}$ while it has been linked with angiogenesis in prostate cancer. ${ }^{27}$ SFRP4 co-expressed with EMT markers in CRC samples and associated with poor prognosis. ${ }^{39}$ The chemokine CXCL9 has a preponderant role in the chemotaxis of immune cells. Its role in carcinogenesis is controversial and seems dependent on histology, disease stage, secreting type of cell and concentration in TME. ${ }^{31}$ These reasons explain the choice to select these three genes for investigation in the Belgian cohort. We were however confronted to technical hurdles caused by the poor RNA quality of our histological FFPE samples, a well-known issue in the literature. ${ }^{40}$ During formalin bath and paraffin embedding, RNA undergoes chemical modifications and fragmentation. The variability of fixation protocols, as well as prolonged storage time further impact RNA degradation. One-third of the samples repeatedly showed an absence of signal in qPCR experiments, despite using a qPCR protocol designed and optimised for breast cancer-derived FFPE RNA. Moreover, oesophageal surgical procedure is long and tumour specimens undergo a protracted devascularisation before entering formol bath procedures. ${ }^{40}$ Taken together, these elements could explain the low DV200 value and sparsed qPCR signals obtained from the samples.

In this context, we were not able to find a difference in expression of these three genes between IGP and EGP samples, although CXCL9 low expression shows a positive prognostic impact, while SFRP4 displays a similar tendency. OLR1 expression, with fewer analysable samples, did not show any prognostic value. 
Altogether, this work pointed several interesting actors involved in HGP development, although limitations remain. The treatments administered to the second cohort might have buffered the role of the key genes identified in the TCGA cohort. Indeed, previous studies showed that preoperative treatment such as chemotherapy could impact the development of HGP, evoking their potential dynamic nature. ${ }^{13} 1441$ Hence, neoadjuvant chemotherapy has been associated with fibrosis and ECM modifications in CRLM. These histological modifications have also been associated with neoadjuvant chemoradiotherapy in OEC, which concerns $25 \%$ of the Belgian cohort. It is thus plausible that treatments might have impacted HGP and their underlying biological mechanisms compared with the results obtained on the treatment-naïve TCGA cohort. Nevertheless, the contingency table analysis did not show differential HGP frequency for patients with or without pretreatment (chemotherapy or chemoradiotherapy). Similarly, we investigated the potential well-known modulatory effect of neoadjuvant treatment on immune profiles, ${ }^{42}$ depending on HGP subtypes: the infiltration of B cells is significantly weaker in IGP samples compared with EGP samples in the chemoradiotherapy group. In head and neck squamous cell carcinoma, a decrease in CD20 is observed after chemoradiotherapy. ${ }^{43}$ Thus, it might be that this effect has a stronger impact on IGP than EGP tumours. However, the small size sample of each subgroup and the lack of information on the functionality of the immune cells impedes further interpretation.

Furthermore, an extensive assessment of several tumorous blocks per patient might lead to the distinction of an intermediate group between EGP and IGP. 'Mixed' CRLM samples, composed partly of desmoplastic and replacement patterns, display a prognosis similar to pure replacement pattern patients. ${ }^{13}$

In conclusion, this study demonstrates the poor prognostic value carried by IGP and suggests key carcinogenetic pathways associated with this pattern. We believe a comprehensive RNAseq analysis of angiogenesis, EMT and inflammation markers might shed light on the intertwined, complex processed leading to HGP development. The poor quality of the RNA extracted from the tissue advocates for the adoption in high-volume centres specialised in oesophageal surgery for a precise protocol concerning the fixation and paraffin-embedding procedure that limit sequencing analysis.

This article underlines the need to consider this clinical parameter when composing clinical cohorts. Moreover, dissecting such pathways may be of interest in the development of precision medicine in OEC, which currently relies mainly on standard systemic therapies.

Acknowledgements The authors would like to thank Soizic Garaud (Molecular Immunology Unit, Institut Jules Bordet, Université Libre de Bruxelles) and Nicolas van Baren (Cellular Genetics Unit, de Duve Institute, Université Catholique de Louvain) for help and advises concerning qPCR experiments and Ghanem Ghanem (Laboratory of Oncology and Experimental Surgery, Institut Jules Bordet, Université Libre de Bruxelles) for access to qPCR facilities.
Contributors MA and PD were involved in conceptualising the study. Clinical data collection was conducted by MA. AD, FS, VD, AH and CV supervised the work, assisted in study conception and clinical data reviewing. Tumour samples retrieval and analyses were performed by MA, MGG and LC, with support from DL. HGP assessment was carried by PD and MA. IHC and qPCR experiments were performed by MA, with help from AD. IHC scoring was performed by RDW and MA. TCGA data retrieval, bioinformatic and statistical analyses were performed by MA, GL and SV, with support from TL. MA, PD and AH led the efforts to write and edit the manuscript, and all authors reviewed the final draft for potential edits prior to submission.

Funding This work was supported by La Fondation Roi Baudouin, Brussels, Belgium. MA is supported by a Belgian FRIA fellowship from Le Fonds de la Recherche Scientifique (FR-FNRS).

Competing interests None declared.

Patient and public involvement statement Patient and public involvement was not considered in this research.

Patient consent for publication Not required.

Ethics approval Approval of the Ethical Committee of Institut Jules Bordet (CE2472) was obtained.

Provenance and peer review Not commissioned; externally peer reviewed.

Data availability statement TCGA data: Data are available in a public, open access repository; Belgian cohort data: No data are available.

Open access This is an open access article distributed in accordance with the Creative Commons Attribution Non Commercial (CC BY-NC 4.0) license, which permits others to distribute, remix, adapt, build upon this work non-commercially, and license their derivative works on different terms, provided the original work is properly cited, appropriate credit is given, any changes made indicated, and the use is non-commercial. See: http://creativecommons.org/licenses/by-nc/4.0/.

\section{ORCID iDs}

Maelle Anciaux http://orcid.org/0000-0001-7801-5171

Pieter Demetter http://orcid.org/0000-0001-7981-4645

Roland De Wind http://orcid.org/0000-0001-8476-1541

Maria Gomez Galdon http://orcid.org/0000-0001-6943-0402

Ligia Craciun http://orcid.org/0000-0001-6540-8232

Denis Larsimont http://orcid.org/0000-0003-2152-253X

Tom Lenaerts http://orcid.org/0000-0003-3645-1455

Francesco Sclafani http://orcid.org/0000-0003-0251-2627

Amélie Deleporte http://orcid.org/0000-0001-6694-0116

Vincent Donckier http://orcid.org/0000-0003-1457-2520

Alain Hendlisz http://orcid.org/0000-0003-2122-1948

Caroline Vandeputte http://orcid.org/0000-0001-7990-8692

\section{REFERENCES}

1 Colotta F, Allavena P, Sica A, et al. Cancer-Related inflammation, the seventh hallmark of cancer: links to genetic instability. Carcinogenesis 2009;30:1073-81.

2 van Dam P-J, Daelemans S, Ross E, et al. Histopathological growth patterns as a candidate biomarker for immunomodulatory therapy. Semin Cancer Biol 2018;52:86-93.

3 Koike M, Kodera Y, Itoh Y. Multivariate Analysis of the Pathologic Features of Esophageal Squamous Cell Cancer: Tumor Budding Is a Significant Independent Prognostic Factor 2008;15:1977-82.

4 Jass JR, Love SB, Northover JM. A new prognostic classification of rectal cancer. Lancet 1987;1:1303-6.

5 Compton C, Fenoglio-Preiser CM, Pettigrew N, et al. American joint Committee on cancer prognostic factors consensus conference: colorectal Working group. Cancer 2000;88:1739-57.

6 Koelzer VH, Lugli A. The tumor border configuration of colorectal cancer as a histomorphological prognostic indicator. Front Oncol 2014:4:1-11.

7 Morikawa T, Kuchiba A, Qian ZR, et al. Prognostic significance and molecular associations of tumor growth pattern in colorectal cancer. Ann Surg Oncol 2012;19:1944-53.

8 Fernández Moro C, Bozóky B, Gerling M. Growth patterns of colorectal cancer liver metastases and their impact on prognosis: a systematic review. BMJ Open Gastroenterol 2018;5:e000217-12.

9 Vermeulen PB, Colpaert C, Salgado R, et al. Liver metastases from colorectal adenocarcinomas grow in three patterns with different angiogenesis and desmoplasia. J Pathol 2001;195:336-42. 
10 van Dam P-J, van der Stok EP, Teuwen L-A, et al. International consensus guidelines for scoring the histopathological growth patterns of liver metastasis. Br J Cancer 2017;117:1427-41.

11 Eefsen RL, Van den Eynden GG, Høyer-Hansen G, et al. Histopathological growth pattern, proteolysis and angiogenesis in chemonaive patients resected for multiple colorectal liver metastases. J Oncol 2012;2012:1-12.

12 Wu J-B, Sarmiento AL, Fiset P-O, et al. Histologic features and genomic alterations of primary colorectal adenocarcinoma predict growth patterns of liver metastasis. World J Gastroenterol 2019;25:3408-25.

13 Galjart B, Nierop PMH, van der Stok EP, et al. Angiogenic desmoplastic histopathological growth pattern as a prognostic marker of good outcome in patients with colorectal liver metastases. Angiogenesis 2019;22:355-68.

14 Frentzas S, Simoneau E, Bridgeman VL, et al. Vessel co-option mediates resistance to anti-angiogenic therapy in liver metastases. Nat Med 2016;22:1294-302.

15 AP B. Who histological classification of oesophageal tumours.

16 Nakanishi Y, Ochiai A, Kato H, et al. Clinicopathological significance of tumor nest configuration in patients with esophageal squamous cell carcinoma. Cancer 2001;91:1114-20.

17 Grossman RL, Heath AP, Ferretti V, et al. Toward a shared vision for cancer genomic data. N Engl J Med 2016;375:1109-12.

18 Cancer Genome Atlas Research Network, Analysis Working Group: Asan University, BC Cancer Agency, et al. Integrated genomic characterization of oesophageal carcinoma. Nature 2017:541:169-75

19 Love MI, Huber W, Anders S. Moderated estimation of fold change and dispersion for RNA-Seq data with DESeq2. Genome Biol 2014;15:1-21.

20 Subramanian A, Tamayo P, Mootha VK, et al. Gene set enrichment analysis: a knowledge-based approach for interpreting genome-wide expression profiles. Proc Natl Acad Sci U S A 2005;102:15545-50.

21 Shannon P, Markiel A, Ozier O, et al. Cytoscape: a software environment for integrated models. Genome Res 2003;13:2498-504.

22 Jassal B, Matthews L, Viteri G, et al. The reactome pathway knowledgebase. Nucleic Acids Res 2020;48:D498-503.

23 Racle J, de Jonge K, Baumgaertner P, et al. Simultaneous enumeration of cancer and immune cell types from bulk tumor gene expression data. Elife 2017;6:1-25

24 Buisseret L, Garaud S, de Wind A, et al. Tumor-Infiltrating lymphocyte composition, organization and PD-1/ PD-L1 expression are linked in breast cancer. Oncoimmunology 2017;6:e1257452.

25 Gu-Trantien C, Garaud S, Migliori E, et al. Quantifying tertiary lymphoid structure-associated genes in formalin-fixed paraffin-embedded breast cancer tissues. Methods Mol Biol 2018;1845:139-57.

26 Lian L, Li X-L, Xu M-D, et al. Vegfr2 promotes tumorigenesis and metastasis in a pro-angiogenic-independent way in gastric cancer. BMC Cancer 2019;19:1-15.
27 González-Chavarría I, Cerro RP, Parra NP, et al. Lectin-Like oxidized LDL receptor-1 is an enhancer of tumor angiogenesis in human prostate cancer cells. PLoS One 2014;9:e106219-11.

28 Nfonsam LE, Jandova J, Jecius HC, et al. SFRP4 expression correlates with epithelial mesenchymal transition-linked genes and poor overall survival in colon cancer patients. World J Gastrointest Oncol 2019;11:589-98.

29 Ford CE, Jary E, Ma SSQ, et al. The Wnt gatekeeper SFRP4 modulates EMT, cell migration and downstream Wnt signalling in serous ovarian cancer cells. PLoS One 2013;8:e54362-7.

30 Metzemaekers M, Vanheule V, Janssens R, et al. Overview of the mechanisms that may contribute to the non-redundant activities of interferon-inducible CXC chemokine receptor 3 ligands. Front Immunol 2017:8:1970.

31 Ding Q, Lu P, Xia Y, et al. Cxcl9: evidence and contradictions for its role in tumor progression. Cancer Med 2016;5:3246-59.

32 Rubie C, Kempf K, Hans J, et al. Housekeeping gene variability in normal and cancerous colorectal, pancreatic, esophageal, gastric and hepatic tissues. Mol Cell Probes 2005;19:101-9.

33 Zhang Y. Epidemiology of esophageal cancer. World J Gastroenterol 2013;19:5598-606.

34 Ito E, Ozawa S, Kijima H, et al. New invasive patterns as a prognostic factor for superficial esophageal cancer. J Gastroenterol 2012;47:1279-89.

35 Zabeck H, Dienemann $\mathrm{H}$, Hoffmann $\mathrm{H}$, et al. Molecular signatures in IASLC/ATS/ERS classified growth patterns of lung adenocarcinoma. PLoS One 2018;13:e0206132-13.

36 Fiori ME, Di Franco S, Villanova L, et al. Cancer-Associated fibroblasts as abettors of tumor progression at the crossroads of EMT and therapy resistance. Mol Cancer 2019;18:1-16.

37 Brunner SM, Kesselring R, Rubner C, et al. Prognosis according to histochemical analysis of liver metastases removed at liver resection. Br J Surg 2014;101:1681-91.

38 Uddin MN, Li M, Wang X. Identification of transcriptional markers and microRNA-mRNA regulatory networks in colon cancer by integrative analysis of mRNA and microRNA expression profiles in colon tumor stroma. Cells 2019;8:1054.

39 Nfonsam L, JAndova J, Jecius $\mathrm{H}$, et al. SFRP4 expression correlates with epithelial mesenchymal transition-linked genes and poor overall survival in colon cancer patients. World J Gastrointest Oncol 2011;1:4-12.

40 von Ahlfen S, Missel A, Bendrat K, et al. Determinants of RNA quality from FFPE samples. PLoS One 2007;2:e1261-7.

41 Mentha G, Terraz S, Morel P, et al. Dangerous halo after neoadjuvant chemotherapy and two-step hepatectomy for colorectal liver metastases. Br J Surg 2009;96:95-103

$42 \mathrm{Ma} \mathrm{J}-\mathrm{lu}$, Jin L, Li Y-D, et al. The intensity of radiotherapy-elicited immune response is associated with esophageal cancer clearance. $J$ Immunol Res 2014;2014:794249.

43 Tabachnyk M, Distel LVR, Büttner M, et al. Radiochemotherapy induces a favourable tumour infiltrating inflammatory cell profile in head and neck cancer. Oral Oncol 2012:48:594-601. 